ADA $(n=11 ; 44 \%)$, IFX $(n=6 ; 24 \%)$, UST $(n=3 ; 12 \%)$, golimumab $(n=3$; $12 \%)$, SCK $(n=1 ; 4 \%)$ and vedolizumab $(n=1 ; 4 \%)$. The indication was intestinal in 4 patients, joint in 8 and both in 13 .

The clinical and analytical evolution in all patients was satisfactory, with a mean ESR of $11.6 \pm 9 \mathrm{~mm} 1^{\mathrm{a}} \mathrm{h}, \mathrm{CRP} 0.6 \pm 0.3 \mathrm{mg} / \mathrm{dL}$ and BASDAI 2 in the last control, after an average time of evolution of $12.5 \pm 9.3$ years.

Conclusion: In this series, IBD was observed in $9.26 \%$ of patients with $\mathrm{SpA}$ of which $64 \%$ were AS. The most frequent form was $\mathrm{CD}$ and it was diagnosed after $\mathrm{SpA}$ in $60 \%$ of the cases. 6 patients were with BT at the time of IBD onset. High FC $(>200 \mu \mathrm{g} / \mathrm{g})$ was observed in the majority of patients.

Therefore, we recommend assessing the presence of digestive manifestations (abdominal pain, weight loss or diarrhea) in patients with SpA due to their possible association with IBD. The FC is a useful tool in these patients.

TABLE 1. CHARACTERISTICS OF IBD IN SPA SUBTYPES

\begin{tabular}{|c|c|c|c|c|}
\hline & $\begin{array}{c}\text { AS } \\
(n=16,64 \%)\end{array}$ & $\begin{array}{c}\text { PsA } \\
(n=6,24 \%)\end{array}$ & $\underset{(n=3,12 \%)}{\text { uSpa }}$ & TOTAL $=25$ \\
\hline MEN/WOMEN & $14 / 2$ & $4 / 2$ & $2 / 1$ & $\begin{array}{c}20 / 5 \\
(80 \% / 20 \%)\end{array}$ \\
\hline $\begin{array}{l}\text { AGE AT IBD DX } \\
\text { (average in years) }\end{array}$ & 37.56 & 45.8 & 34 & 39.12 \\
\hline HLA B27+ (n, pationts) & 13 & 1 & 1 & 15 \\
\hline CD/UC/IC (n, pationts) & $9 / 6 / 1$ & 2/2/2 & $2 / 1 / 10$ & $\begin{array}{c}13 / 9 / 3 \\
(52 \% / 36 \% / 12 \%)\end{array}$ \\
\hline ESR (average in $\mathrm{mm}^{1} \mathrm{P}^{\mathrm{h}}$ ) & 30.07 & 39.75 & 21.5 & 31.15 \\
\hline CPR (avorago in $\mathrm{mg} / \mathrm{dL}$ ) & 2.44 & 3.08 & 3.42 & 2.7 \\
\hline $\begin{array}{ll}F C \text { (avorage in } \mu \mathrm{g} g \mathrm{~g}) \\
\end{array}$ & 369.2 & 409.67 & 1009 & 459.29 \\
\hline 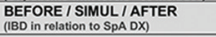 & 6/2/8 & $0 / 0 / 6$ & 1/1/1/1 & $\begin{array}{c}7 / 3 / 15 \\
(28 \% / 12 \% / 60 \%)\end{array}$ \\
\hline BT AT IBD DX (n, pationts) & 3 & 2 & 1 & 6 \\
\hline BT & $\begin{array}{l}\operatorname{ETN}(n=1), \\
\operatorname{IFX}(n=1), \\
\operatorname{SCK}(n=1)\end{array}$ & $\begin{array}{l}\text { ADA }(n=1), \\
\text { UST (n=1), }\end{array}$ & ETN $(n=1)$ & 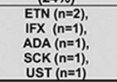 \\
\hline
\end{tabular}

TABLE 2. BT IN 270 PATIENTS WITH SPA.

\begin{tabular}{|c|c|c|c|}
\cline { 2 - 4 } \multicolumn{1}{c|}{} & Patients $(\mathbf{n})$ & $\begin{array}{c}\text { IBD development } \\
\text { after BT }(\mathbf{n})\end{array}$ & $\begin{array}{c}\text { IBD development } \\
\text { after BT (\%) }\end{array}$ \\
\hline ETN & 57 & 2 & $3.50 \%$ \\
\hline ADA & 98 & 1 & $1.02 \%$ \\
\hline IFX & 36 & 1 & $2.78 \%$ \\
\hline SCK & 22 & 1 & $4.54 \%$ \\
\hline UST & 15 & 1 & $6.67 \%$ \\
\hline CZP & 25 & 0 & $0 \%$ \\
\hline GLM & 15 & 0 & $0 \%$ \\
\hline VDZ & 2 & 0 & $0 \%$ \\
\hline TOTAL & 270 & 6 & $2.22 \%$ \\
\hline
\end{tabular}

BT: biological therapy, IBD: inflammatory bowel disease, ETN: etanercept, ADA: adalimumab, IFX: infliximab, SCK: secukinumab, UST: ustekinumab, CZP: certolizumab, GLM: golimumab, VDZ: vedolizumab

Disclosure of Interests: None declared

DOI: 10.1136/annrheumdis-2019-eular.4427

\section{SAT0321 CARDIOVASCULAR EVENTS IN SPONDYLOARTHRITIS A META-ANALYSIS}

Jihyoun Kim, In Ah Choi. Chungbuk National University Hospital, Rheumatology department, internal medicine, Cheoungju-si, Chungcheongbuk-do, Korea, Rep. of (South Korea)

Background: Several studies have demonstrated the possibility of increased risk of cardiovascular disease in patients with inflammatory arthritis such as anklyosing spondylitis and rheumatoid arthritis. In recent years, studies using population -based cohort and insurance claim data have been actively conducted.

Objectives: To compare risks for cardiovascular disease including myocardial infarction (MI), ischemic heart disease (IHD), stroke and mortality of spondyloarthritis compared to general population using large-scale data. Methods: A systematic search was performed in MEDLINE, EMBASE with additional manual searches for studies associated with spondyloarthritis published between January 1997 and October 2018. All search screening and data collection were performed independently by two reviewers. We calculated the incidences of $\mathrm{MI}$, IHD, stroke and mortality in a meta-analysis of proportion and determined risk ration (RR) by Mante-Haenszel method.
Results: We identified total 495 articles and 16 articles met criteria for meta-analysis including 13 anklyosing spondylitis (AS) studies, 3 psoriatic arthritis (PsA) studies and 1 undifferentiated spondyloarthritis study. The articles were based on large-scale data such as national population cohort or insurance claim data. A meta-analysis result showed a significant increase in the risk of $\mathrm{Ml}(\mathrm{RR}=1.38 ; 95 \% \mathrm{Cl} 1.18$ to 1.61$)$, and stroke $(R R=2.04 ; 95 \% \mathrm{Cl} 1.11$ to 3.78$)$ in spondyloarthritis patients com pared to general population. However, mortality related with cardiovascular disease $(R R=1.19 ; 95 \% \mathrm{Cl} 0.96$ to 1.48$)$ and total mortality $(R R=1.31$ $95 \% \mathrm{Cl} 0.8$ to 2.15 ) results did not show significant increases in spondy loarthritis patients.

Conclusion: Our meta-anaylsis results showed that the the risk of $M$ and stroke significantly increased although mortality associated with cardiovasular (CV) disease and overall mortality did not increase in spondyloarthritis compared to general population. These findings support the reduction of inflammation as well as the management of traditional cardiovascular disease risk factors may reduce $\mathrm{CV}$ risk in patients with spondyloarthritis.

\section{REFERENCES}

[1] Szabo SM, Levy AR, Rao SR, et al. Increased risk of cardiovascular and cerebrovascular diseases in individuals with ankylosing spondylitis: a population-based study. Arthritis Rheum 2011; 62: 3294-304

[2] Park CJ, Choi YJ, Kim JG, et al. Association of acute myocardial infarction with ankylosing spondylitis: a nationwide longitudinal cohor study. Journal of Clinical Neuroscience 2018; 56: 34-37.

[3] Bengtsson, K, Forsblad-d'Elia H, Lie E, et al. Are ankylosing spondylitis, psoriatic arthritis and undifferentiated spondyloarthritis associated with an increased risk of cardiovascular events? A prospective nationwide population-based cohort study. Arthritis Res Ther 2017; 19:102

Disclosure of Interests: None declared

DOI: 10.1136/annrheumdis-2019-eular.6597

\section{SAT0322 AXSPA PATIENTS WITH SYMPTOM ONSET $<30$ YEARS HAVE MORE STRUCTURAL LESIONS ON MRI OF THE SACROILIAC JOINTS WHEN FULFILLING THE MODIFIED NEW YORK CRITERIA}

1,2 Manouk de Hooge, Ann-Sophie De Craemer ${ }^{1,2}$, Thomas Renson ${ }^{1,2}$ Philippe Carron ${ }^{1,2}$, Liselotte Deroo ${ }^{1,2}$, Dirk Elewaut ${ }^{1,2}$, Filip van den Bosch ${ }^{1,2} .{ }^{1} U Z$ Gent, Ghent, Belgium; ${ }^{2}$ VIB Inflammation Research Center, Ghent, Belgium

Background: The modified New York criteria (mNY) combine clinical symptoms with radiographic sacroilitis on conventional pelvic radiographs (X-SI) classifying radiographic axial SpA patients ( $r$-axSpA). AxSpA is known to typically start in the third era of life but there is a diagnostic delay of \pm 7 years. As the mNY criteria classify the most typical and severe expression of axSpA it is suggested that the mNY criteria are less useful in younger patients.

Objectives: To explore the diagnostic utility of the mNY criteria in newly diagnosed axSpA patients with a symptom onset $<30$ years. In addition, describe the extent of lesions on MRI of the sacroiliac joints (MRI-SI) in $\mathrm{mNY}$ positive $(\mathrm{mNY}+)$ patients with a symptom onset $<30$ years.

Methods: This study involved newly diagnosed axSpA patients, age $>18$ years, from a Belgian (Be-Giant) cohort. Patients underwent diagnostic tests involving clinical examination, lab tests, and imaging assessment containing an X-SI and an MRI-SI. mNY criteria was assessed on X-SI. MRI-SI reads contained the assessment of inflammatory lesions according to the Spondyloarthritis Research Consortium of Canada (SPARCC) scoring method and erosions, fatty lesions (FL), sclerosis, ankylosis using an adapted method of the SPARCC. Also, the ASAS definition of a positive MRI-SI was evaluated. T1-weighted and STIR images were viewed simultaneously. X-SI and MRI-SI were evaluated independently by 3 trained readers who were also blinded for clinical features. Imaging scores (X-SI grading according to the $\mathrm{mNY}$ criteria and $\mathrm{mNY}$ fulfillment, and MRI-SI lesion scores) were calculated as 2 out of 3 reader scores.

Results: In the 173 patients with available X-SI, the average age at symptom onset was 27.4 years old. In $114 / 173$ (65.9\%) patients, the symptom onset was below 30 years. Of those, 11 (9.6\%) patients fulfilled the mNY criteria. Seven of the $11(63.6 \%)$ patients that were $\mathrm{mNY}+$ were male, which was slightly lower than in the mNY- patients $(n=55$; $53.4 \%)$. The presence of HLA-B27 was comparable between $\mathrm{mNY}+$ and mNY- patients; $8(72.7 \%)$ patients and $82(79.6 \%)$ patients, respectively. Average $\mathrm{X}$-SI grading in $\mathrm{mNY}$ + patients was $4.7 \pm 1.3$ (on a scale from 0 8 ) and in mNY negative (mNY-) patients $(n=103)$ the average $X-S I$ grading was 1.1 1 1.1. When looking at the MRI-SI assessment, 8/11 mNY 